\title{
BULLYING E A REALIDADE ESCOLAR
}

Andrea Ludugel FAGUNDES ${ }^{1}$

Gleicione Ap ${ }^{\mathrm{a}}$ Dias Bagne de SOUZA ${ }^{2}$

\author{
Recebido em: 30/10/2013 - Aprovado em: 18/12/2013 - Disponibilizado em: 15/01/2014
}

\begin{abstract}
RESUMO
Este artigo visa compreender o princípio do respeito e das nossas diversidades culturais, através da atuação do professor em sala de aula e no seu cotidiano da vida escolar, instalando uma educação mais democrática, na qual, seja respeitada as diferenças físicas, ideológicas, culturais e socio-econômicas, contribuindo para uma sociedade mais justa e mais igualitária. O Bullying é um problema mundial, sendo encontrado em toda e qualquer escola, não estando restrito a nenhum tipo específico de instituição: primária ou secundária, pública ou privada, rural ou urbana. São todas as formas de atitudes agressivas, intencionais e repetidas, que ocorrem sem motivo evidente, adotadas por um ou mais estudantes contra outro, causando dor e humilhação. Portanto, os atos repetidos entre eles (estudantes) e o desequilíbrio de poder são as características marcantes, que tornam possível a intimidação da vítima. Quando não existem uma chamada contra o Bullying, o ambiente escolar se torna contaminado e ameaçador. Todas as crianças, sem exceção, são afetadas negativamente, passando a experimentar sentimentos de ansiedade, medo e revolta. Portanto, é nosso objetivo conscientizar e mostrar aos educadores, famílias e sociedade para a existência real do problema e suas consequências, buscando a tomada de estratégias e decisões para a solução frente a esse comportamento, onde nossos alunos possam frequentar uma escola segura, solidária e democrática, capaz de gerar cidadãos conscientes do respeito ao seu próximo e as diversidades culturais frente as diferenças.
\end{abstract}

PALAVRAS-CHAVE: Bullying. Escola. Vítima. Alunos.

\begin{abstract}
This work aims to understand the principle of respect and our cultural diversity, through the actions of the teacher in the classroom and in their everyday life at school, building a more democratic education, which the physical, ideological, cultural and socioeconomic differences are respected, contributing to a fairer and more egalitarian society. The "Bullying" is a worldwide problem, being found in any school, not restricted to any particular type of institution: primary or secondary, public or private, rural or urban. Are all forms of aggressive attitudes, intentional and repeated, which occur without apparent reason, taken by one or more students against another, causing pain and humiliation. Therefore, the repeated acts between them (students) and the imbalance of power are the characteristics that make possible the intimidation of the victim. When there is no punishment against Bullying, the school environment becomes contaminated and threatening. All children, without exception, are adversely affected and will experience feelings of anxiety, fear and anger. Therefore, our goal is to awareness the educators, families and society to the real existence of the problem and its consequences, seeking and taking strategies and decisions to solution this behavior, where our students can attend a safe, caring and democratic school, able to generate citizens aware of its cultural diversity.
\end{abstract}

KEYWORDS: Bullying. School. Victim. Students.

\footnotetext{
${ }^{1}$ Pedagoga e Pós-graduada em Psicopedagogia Institucional e Clínica.

${ }^{2}$ Pedagoga, Mestre em Engenharia de Produção com ênfase em Mídia e Conhecimento e Doutora em Educação. 583 


\section{INTRODUÇÃO}

Apesar do termo BULLYING há pouco tempo está sendo conhecido, seus atos são bem antigos, " é de difícil identificação, principalmente por manifestar-se de maneira sutil e velada e por garantir sua propagação através da imposição da lei do silêncio" (FANTE, p.92, 2005), são bastante traumáticos que vem crescendo a cada dia em nossa sociedade. (SILVA, p.1, 2008), define Bullying como "palavra da língua inglesa que significa gozar, humilhar, intimidar, ofender, agredir, discriminar, e colocar epitélios em determinado indivíduo". Mas, o que leva os agressores a fazer uso da violência física e/ou psicológica? Ao investigar as causas, evidenciamos que são vários os fatores que a determinam: "Distúrbios Comportamentais" (indisciplina) causado por questões relacionadas ao professor em sala de aula; ou centrados nas famílias; ou gerados no processo pedagógico escolar; e outros alheios ao contexto escolar.

Geralmente, o caso Bullying ocorre com grande frequência nas escolas, a escola não pode fechar os olhos, tratando com indiferença e descaso tal acontecimento, antes precisa estar atenta "tendo uma conduta aviltante, resguardando tanto os agressores quantos os agredidos, pois o autor do bullying já foi anteriomente alvo" (SILVA, p.1, 2008). Num lugar onde a diversidade cultural com diferentes realidades sociais se encontram, precisam do respeito mútuo, "ao dever de respeitar o outro articula-se o direito, a exigência de ser respeitado”. (BRASIL, p.96, 1996).

Segundo Queiroz "é comum os indivíduos que são discriminados manifestarem sentimentos de inferioridade e sintomas de melancolia, depressão, infelicidade, ressentimento, insegurança e pessimismo"( 1996, p.40). Como a discriminação está relacionado com algum tipo de Bullying, nos faz pensar que algumas dificuldades de aprendizagem e relacionamento social pode estar de alguma forma ligados a quem sofre ou sofreu este tipo de agressão.

Por isso, é necessário trazer e despertar o interesse de pais e educadores, mostrando que pai ou professor, é o educador, portanto ter um olhar diferenciado e uma "visão de alteridade: Olhar o outro como o outro é e não como um estranho" (CORTELA, p.31, 2005), ou seja, uma das funções do professor é conhecer melhor seus alunos, e os pais seus filhos, procurando assim enfrentar conflitos do seu cotidiano, tentando solucioná-los vivendo bem e em harmonia.

O objetivo deste artigo é identificar os fatores contribuintes causadores do bullying. Qual o papel da escola, sua função política diante da sociedade por uma escola mais justa e igualitária? Qual a postura do educador frente aos problemas do bullying? A 
reflexão do professor diante de suas ações no âmbito escolar, mudança de estratégias quando for necessário para solucionar os conflitos deste comportamento. O aluno está fazendo parte da comunidade escolar, vivenciando e experimentando às diferenças culturais, o preconceito, o ser diferente, a discriminação, tornado-se um cidadão reflexivo, justo e que respeita seu próximo?

A escola é um ambiente educador e socializador. Mas temos que lembrar que a responsabilidade é de todos, família, escola e sociedade. E na grande maioria das vezes, a escola assume um papel da educação integral de seus alunos.

A educação, dever
da família e do
Estado, inspirada
nos princípios de
liberdade e nos
ideais
solidariedade de
humana, tem por
finalidade o pleno
desenvolvimento do
educando, reu
preparo para o
exercício ra da
cidadania e sua
qualificação para o
trabalho. LDB (Lei
$n^{\circ}$ 9394/96, em seu
título II, artigo $2^{\circ}$ ).

\section{O que é BULLYING?}

"Bullying é uma palavra da língua inglesa que significa gozar, humilhar, intimidar, ofender, agredir, discriminar e colocar epitetos maliciosos em determinado indivíduo. É um conjunto de atitudes hostis propositadas, recorrentes e sem causa manifesta, empreendido por um sujeito (ou grupo) que ocasiona aflição a outrem" (SILVA, p.1, 2008).

"A escola não pode camuflar tal acontecimento, habitualmente percebível em seus domínios, educadores precisam estar atentos e ser observadores, e atuar quando se fazer necessário (SILVA, p.1, 2008). Os locais onde ocorrem práticas de vitimação e agressão são os mais variados.

Podemos dividir entre dois tipos de Bullying:

- Direto: a vítima é atacada frente a frente.

- Indireto: a vítima é atacada por outros meios. Como por exemplo, com boatos maldosos, ou praticado por meios eletrônicos, sites de relacionamento, e-mails, blogs (os diários virtuais), pagers e celulares, para denegrir a imagem do próximo, através de mensagens difamatórias ou ameaçadoras. (CHALITA, p.82, 2008).

As consequências são desde danos morais e/ou físicos, resultando até mesmo em sérias depressões e doenças do tipo. Alguns sinais são habitualmente observados, como hematomas não justificados, objetos em falta, livros rasgados, necessidade de material escolar ou de dinheiro extra. Para acompanhar esses acontecimentos é necessário a presença indispensável dos pais.

Acrescentando ao plano psicológico é comum que os indivíduos dos grupos discriminados manifestem sentimentos de 
inferioridade e sintomas de melancolia, depressão, infelicidade, ressentimento, insegurança e pessimismo. (QUEIROZ, p.40, 1996).

A escola deve ser um lugar onde os valores morais são pensados, refletidos e não meramente impostos ou frutos do hábito; deve ser o local onde os alunos desenvolvam a arte do diálogo (BRASIL, p.71, 1996).

A falta de preparação dos dirigentes da escolas é grande. Muitas vezes, os professores assistem a casos de violência, mas acabam por repreender ao agressor e à vítima, sem avariguar os reais motivos que levaram a essa discussão. Isso, faz com que a vítima se sinta revoltada ao ser criticada e punida por algo do qual não tem culpa, e mais tarde, acaba servindo de pretexto para novas agressões, uma vez que foi "por causa" da vítima que o agressor foi punido. Ou em outro momento, o educador age com indiferença, fazendo com que a impunidade seja a causa da frustação da vítima, dando continuidade às agressões. E esta por sua vez, pode ser adicionada ao contexto da história como mais um Bully.

As vítimas que sofrem ou já sofreram algum tipo de violência, podem não superar os traumas sofridos na escola, tendo um baixo rendimento escolar. Crescendo com sentimentos negativos e apresentar baixa autoestima, sérios problemas de relacionamento, e se auto excluir da sociedade em que vive, desenvolvendo um comportamento agressivo também quando adulto, podendo vir a adotar comportamentos criminosos. (SILVA, p. 02, 2006).

\subsection{O Ser Diferente}

Nos dias atuais, se discute as questões como a atenção à igualdade e a diferença entre os seres humanos (pessoas com deficiência), grupos culturais e classes sociais. Mas existe uma contrariedade: enfrentamos situações em que se negam e desrespeitam os direitos dos seres humanos, e há o domínio do preconceito e a violência. Pois, para o ser humano a maneira como agir em relação aos outros, às suas diferenças, é ainda, um grande desafio.

Um dos preconceitos (exemplo de desrespeito) são os indivíduos com deficiência física ou mental, que estão presentes nas escolas e que mais tarde, tentam entrar no mercado de trabalho, mas são "barrados", devido a discriminação cultural da sociedade.

Os gregos criaram um termo que qualquer pessoa que nascesse diferente, era rotulada como uma pessoa anormal, um castigo de Deus, ou seja, refletia nela o espelho de sua alma. Nos dias de hoje, isso ainda acontece. Veridicamente, uma mãe escondeu sua filha da sociedade durante muitos anos, devido a vergonha de sua deficiência, Síndrome de Down. 
"Se Deus marcou, não foi a toa" (QUEIROZ, p.66, 1996), um ditado popular, que resume o desrespeito ao diferente, que mostra a ignorância em relação aos deficientes na sociedade. Mas, de acordo com os preceitos de justiça, todo indivíduo tem o direito da liberdade de ir e vir, de pensamento e fé, de propriedade; direitos sociais, de bem estar econômico. Levando em conta a felicidade de todos ${ }^{3}$.

Logo ao nascer, o ser humano se depara com regras e valores. A família é o primeiro espaço de convivência da criança, mas não será o único. Outras instituições e os meios de comunicação ( $\mathrm{TV}$, rádio, revistas, e outros) irão desempenhar um papel na formação moral e no desenvolvimento de suas atitudes, além de exercer um grande poder de influência sob seu comportamento. (BRASIL, p. 62, 1996).

A escola é uma instituição importante na vida do indivíduo. Abrange a aprendizagem de diversas áreas de conhecimento e leva o aluno ao "convívio escolar", convivendo com pessoas diferentes, na diversidade cultural e com diferentes realidades sociais. Brancos, negros, meninos e meninas, pessoas de renda familiar desigual, alguns com limitações de desempenho, outros talentosos em algumas habilidades, de diversas religiões etc. Todos têm o direito à educação igualitária e democrática, assim, como o respeito e a valorização de cada indivíduo em sua singularidade.

$\mathrm{O}$ que se contempla o sentido do respeito mútuo, é permitir que cada indivíduo possa expressar seus sentimentos e emoções, e admitir suas dúvidas sem ter medo de ser ridicularizado. Com isso, aproveitando algum fato ocorrido em sala de aula, os educadores podem discutir e debater sobre histórias passadas, das consequências de vários tipos de discriminação e preconceito, ensinando e conscientizando o aluno nos valores de que todos devem ser tratados com dignidade, levando também o aluno à potencializar o seu comportamento de forma positiva. De modo particular, Kant, concebia a dignidade como parte da autonomia ética do ser humano, afirmava que ele não poderia ser tratado nem por ele próprio - como objeto. (KANT, p.69, 1986).

O respeito ganha seu significado mais amplo quando se realiza como respeito mútuo, ao dever de respeitar o outro articulase o direito, a exigência de ser respeitado. (BRASIL, p.96, 1996).

Analisando as leis que regem a natureza e que atuam nos aspectos da evolução, o indivíduo é um ser em constante transformação que precisa de um conjunto de normas e regras que o oriente e o guie, regras ou normas adquiridas por hábito. Quanto a sociedade em que vive, esta utiliza alguns mecanismos para a sua prática moral, como a

\footnotetext{
${ }^{3}$ Segundo a Ética, é impossível ser feliz sozinho.
} 
religião, a igreja, a polícia, a política, ideologias, entre outros.

O comportamento moral é próprio do homem com ser histórico, social e prático, ou seja, como um ser que transforma conscientemente o mundo que o rodeia; que faz da natureza externa um mundo a sua medida humana, e que, desta maneira, transforma a sua própria natureza.

Nas Sagradas Escrituras, é citado que Deus criou o homem à sua imagem e semelhança (Gênesis 1:26; Deuteronômio 7:6), e uma das faculdades de Deus é a liberdade de escolha, a dádiva do livre arbítrio, dado como parte de nossa constituição. Junto a isso, adquirimos a habilidade de pensar, avaliar as coisas, tomar decisões e distinguir o certo do errado. Assim, o ser humano deveria basear-se em escolhas inteligentes, não deixando ser arrastado por impulsos ignorantes, diferenciando o mal do bem. Não fomos feitos como robôs que não pensam, sem vontade própria. Tampouco fomos criados para agir por instinto, como os animais. Em vez disso, nosso maravilhoso cérebro foi projetado para operar em harmonia com a nossa liberdade de escolha.

$$
\text { É correto o indivíduo, que controla }
$$
seus impulsos, suas inclinações e suas paixões, que discuta consigo mesmo e com os outros o sentido dos valores, responde pelo que faz, julga suas próprias intenções e recusa a violência contra si e contra os outros. Entendendo-se o significado da palavra liberdade como a capacidade de se autodeterminar. "A liberdade em geral significa poder fazer ou não fazer alguma coisa; chamada de livre - arbítrio, é o poder que a vontade possui de determinar a si mesma e, por si mesma, a agir ou não agir, sem ser a isto coagida por nenhuma força nem interior, nem exterior;" (CAMARGO, p.54, 1999).

\subsection{Fator Preconceito}

Nós não nascemos preconceituosos. (QUEIROZ, p.58, 1996).

Segundo o dicionário Aurélio (p.404), preconceito define-se como "um juízo préestabelecido, baseado em mera crença ou opinião, que formamos devidamente a realidade sobre a qual nos manifestamos". Pré-conceito vem de "conceito prévio", então, resumindo é a antecipação de uma ideia errada que pode prejudicar alguém com um julgamento equivocado.

O indivíduo não nasce preconceituoso, inconscientemente as crianças vão absorvendo as noções de preconceito, por não saberem avaliar de maneira crítica o que a sociedade lhe apresenta.

A ideia de que algumas
pessoas
educação recebida na
infância) estariam mais
predispostas a serem
preconceituosas formou-se
com a teoria da


Personalidade Autoritária ${ }^{4}$, desenvolvida no período após a Segunda Guerra Mundial por Adorno e colaboradores. Um indivíduo com personalidade autoritária seria rígido em suas crenças e opiniões, intolerante para com demonstrações de fraqueza (em si e nos outros), pronto a abraçar valores convencionais,

desconfiado (de ideias ou pessoas diferentes), propenso a adotar medidas punitivas, respeitoso $\mathrm{e}$ submisso a figuras de autoridade de seu grupo, além de rejeitar pessoas que não fazem parte de seu círculo de relações. (ADORNO, p.31, 1950).

Dentre as críticas levantadas contra esta teoria podemos citar o fato de que pais preconceituosos tendem a criar filhos preconceituosos, independente do tipo de educação que seja utilizada em casa. Visto que crianças se identificam com seus pais e com frequência imitam seus comportamentos, não é difícil supor que acabem aprendendo a serem preconceituosas desde cedo, mesmo que não adquiram uma personalidade autoritária no futuro.

De acordo com Queiroz (p.57, 1996), algumas frases citadas por adultos como: "Homem não chora"; "você deve aprender a cozinhar, para que possa se casar"; "Lugar de mulher é na cozinha"; "os negros tem o

4 O grau de autoritarismo de um indivíduo em particular pode ser aferido através de um instrumento chamado de Escala $F$ (a letra $F$ representando a palavra fascismo), criado pelo próprio Adorno e seus colaboradores. samba no sangue"; "eu odeio os judeus"; "os nordestinos são todos preguiçosos"; "coitada da fulana casou-se com um preto"; "você fez um serviço de preto"; resumem exatamente o significado da palavra Preconceito.

Em nosso país o racismo é camuflado, ou seja, branco repele negro, negro repele branco que repele índio, que repele negro que repele japonês, etc. As raças reprimidas são a parte mais numerosa do país e a mais pobre, isso porque o racismo dificilmente irá permitir que essas classes sociais tenham uma vida digna.

A origem do preconceito é uma das grandes dificuldades que o ser humano enfrenta para entender como respeitar e amar o próximo de forma objetiva e sensata.

Uma única experiência
negativa que tenhamos tido
com um indivíduo de
determinado grupo pode
levar-nos a generalizar,
isto é, a estender a todos os
integrantes daquele grupo
um conceito - ou melhor,
um preconceito -
desfavorável. (QUEIROZ,
p.19, 1996).

O problema ocorre entre alunos e também entre professores. Mas, o papel do professor é importantíssimo pois, deve ser modelo, guia, referência (seja para ser seguido ou contestado); mas os alunos podem aprender a lidar com o conhecimento também com os colegas. Uma coisa é o conhecimento "pronto", sistematizado, outro, bem diferente, é este conhecimento em movimento, 
tencionado pelas questões da existência, sendo montado e desmontado (engenharia conceitual). Aprende-se a pensar, ou, se quiserem, aprende-se a aprender. (VASCONCELLOS, 2001).

Assim cabe uma postura mais consciente e firme aos educadores, contra essa cultura de agressividade, identificando e combatendo as atitudes que comprometam o convívio escolar, pois, um dos objetivos da escola é propor ao seu aluno, um ambiente escolar saudável, alegre e harmonioso, sendo assim um local privilegiado por haver diversidade, onde o aluno aprenderá a resolver seus conflitos, interagindo com os demais, conhecendo uma maneira positiva de enfrentar a vida e construindo bases sólidas de justiça e solidariedade.

Todavia, a escola não é somente o meio onde as mazelas sociais são reforçadas, ela é também, fonte para se discutir os dilemas urgentes da humanidade. Entre esses dilemas se encontra a questão do racismo, e os atores escolares precisam enxergar esse potencial catalisador da educação no combate ao mesmo. A escola, como cenário fértil para os grandes debates, precisa se assumir, por meio de seus componentes, como uma protagonista na luta contra qualquer tipo de discriminação. Está na possibilidade da sua intervenção no mundo, para transformá-lo em um lugar melhor, ajudando o ser humano a desenvolver suas potencialidades, sem distinção racial ou de qualquer outra natureza.
Sobre esse estar no mundo de maneira interventiva, Freire (p. 85-86, 1996) afirma: “[...] meu papel no mundo não é só o de quem constata o que ocorre, mas também o de quem intervém como sujeito de ocorrências". Ser um sujeito de ocorrências é partir para o confronto direto com a raiz dos problemas e não ficar fazendo rodeios, evitando assim o conflito de ideias.

\subsection{Escola democrática e igualitária}

A escola em sua função política deve exercer um "compromisso de educar seus alunos dentro dos princípios democráticos". (BRASIL, p.63, 1996).

Uma escola democrática e igualitária abre espaço para que o aluno possa expor suas ideias e pontos de vistas diferentes, nas tomadas de decisões, possibilitando

Qualidade das relações
interpessoais na escola e
relações de cooperação, de
diálogo, levando a
autonomia, ou seja, a
capacidade de pensar, sem
a coerção de alguma
autoridade questionável. A
democracia é um modo de
convivência humana e os
alunos devem encontrar na
escola a possibilidade de
vivenciá-la.
p.66.1996).

Segundo Queiroz,

Toda e qualquer forma de discriminação marginaliza, afasta indivíduos ou grupos da participação plena na vida sócio- 
econômica e cultural, produzindo desigualdades e restringindo o acesso dos que são discriminados às oportunidades de trabalho, escolarização, cultura, lazer e ascensão social (p.39, 1996).

$\mathrm{O}$ autor nos mostra como a discriminação e o preconceito faz com que aumente a desigualdade social e acabe com as oportunidades de uma vida mais digna a todos, onde podemos ter direitos iguais independente do grupo social a qual ela pertence.

O desafio dos educadores é proporcionar aos seus alunos meios, estratégias fazendo- os experimentar no seu dia a dia esta democracia para que eles possam construir sua cidadania no espaço escolar, legitimando seu papel político na sociedade, desenvolvendo sua auto-critica e função social.

"Se o objetivo é contribuir para a formação de indivíduos que tenham respeito pelas diferenças entre as pessoas, não basta belos discursos sobre este valor: é necessário que possam experenciá-lo no seu cotidiano, ser cada um respeitado no que tem de peculiar em relação aos outros". (BRASIL, p.74.1996).

\section{Considerações Finais}

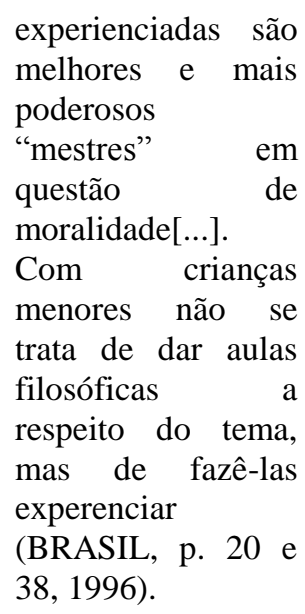

Conscientizar alunos, pais e o corpo docente da escola não basta. É necessário incentivar o aluno a adotar práticas saudáveis, longe de atitudes que tragam prejuízo para ele e seus colegas; "Sensibilizar e envolver toda a comunidade escolar na luta para redução do comportamento bullying torna-se tarefa imprescindível, uma vez que o fenômeno é complexo e de difícil identificação, principalmente por manifestar-se de maneira sutil e velada e por garantir sua propagação através da imposição da lei do silêncio". (FANTE, p.92, 2005).

É necessário que todo o corpo docente da escola adote uma mesma linguagem, ensinando e vivenciando princípios fundamentais para o bom relacionamento do ser humano.
As relações sociais efetivamente vividas
O fato é que o homem tem a propensão de viver junto com os outros, seus semelhantes, e comunicarse com eles tornando-os participantes de suas próprias experiências e desejos, ficando portanto, mais próximos deles, 
convivendo e partilhando emoções e bens. (CAMARGO, p.108, 1999).

Reconhecida a necessidade de proximidade entre os seres humanos, é de extrema importância que se esclareça o assunto teoricamente, além de elaborar estratégias para a execução de práticas que concretizem os alvos propostos pela escola para o combate ao bullying.

Trabalhar valores relacionados entre si, é instrumento fundamental para minimização ou erradicação da prática do bullying em vários ambientes, inclusive $\mathrm{o}$ escolar. "Respeito mútuo, justiça, solidariedade e diálogo" (BRASIL, p.95, 1996) podem ser excelente ponto de partida à construção de relacionamentos saudáveis, habilitando aluno, família, escola, comunidade em geral para um melhor balizamento das ações humanas.

A escola pode reservar tempo e espaço em seus programas para iniciar os alunos em projetos de cooperação. A participação de professores e alunos em projetos comuns pode dar origem à aprendizagem de métodos de resolução de conflitos e construir uma referência para a vida futura dos alunos, enriquecendo a relação professor - aluno, sendo a influência dessa teoria altamente positiva, chamando a atenção para a capacidade dos alunos em se relacionar bem com os outros e consigo mesmo.
O professor poderá atuar com mais eficácia em sua ação pedagógica, conhecendo bem seus alunos, em seus aspectos sociais, afetivos e emocionais. Tomando uma atitude de permanente investigação, por meio de observações, diálogos com os alunos e suas famílias, avaliação contínua dos conhecimentos adquiridos, sondagem dos interesses delas e atenção as necessidades que elas expressam, percebendo o que cada um sente, pois a partir do momento em que o professor reconhece as emoções do aluno (medo, raiva, ciúme, alegria, tristeza, vergonha), cria uma enorme chance de aumentar a intimidade, transmitir experiência e compartilhar dificuldades.

Um dos temas que a escola precisa trazer cada vez mais para o cotidiano dos alunos é a visão de alteridade: olhar o outro como o outro e não como estranho. Entender a alteridade é ser capaz de olhar o outro como o outro é e não como estranho. (CORTELA, 2005).

O aluno passa a se sentir valorizado, legitimado em seus sentimentos (mesmo que negativos) e, consequentemente, fortalece sua auto-estima. Ele descobre novas estratégias para lidar com os conflitos, diminui a agressividade em suas relações com o outro, aprende a conviver de uma maneira confortável com os sentimentos negativos, enfim, ele transforma um sentimento que o assusta em algo que faz parte da vida, não censurando a si mesmo por seus sentimentos, 
mas sim, julgando a decisão do que fazer com estes mesmos sentimentos.

\section{REFERÊNCIAS}

ADORNO, T. W. The Authoritarian personality. New York: Harper \& Brothers, 1950.

BÍBLIA SAGRADA. Tradução Centro Bíblico Católico. $99^{\circ}$ ed. São Paulo: Editora Ave Maria Ltda, 1995. Gênesis 1:26 e Deuteronômio 7:6.

BRASIL. Ministério da Educação e Desporto. ( Secretaria do Ensino Fundamental) Parâmetros Curriculares Nacionais: convívio social e ética - temas transversais. Versão agosto/ 1996.

CAMARGO, Marculino. Fundamentos de ética geral e profissional e Fundamentos objetivos da Ética: Aspectos do ser humano. Petrópolis: Vozes, 1999.

CHALITA, Gabriel. Pedagogia da Amizade - bullying: o sofrimento das vítimas e dos agressores. 2. ed. São Paulo: Gente, 2008.

CORTELA, Mário Sérgio: TAILLE, Yves de la. Nos Labirintos da Moral. Campinas, SP: Papirus, 2005. ( Papirus Debates).
FANTE, Cleo. Fenômeno Bullying: como prevenir a violência nas escolas e educar para a paz. São Paulo: Versus, 2005.

FERREIRA, Aurélio B. de Holanda. Dicionário aurélio básico da língua portuguesa. Rio de Janeiro: Editora Nova Fronteira S.A., 1988.

FREIRE, Paulo. Pedagogia da Autonomia: Saberes Necessários à Prática Educativa. 31.ed. São Paulo: Paz e Terra, 1996.

KANT, E. Fundamentação da Metafísica dos Costumes. Trad. Paulo Quintela. Lisboa: Edições 70, 1986.

\section{LDB, Lei de Diretrizes e Bases da}

Educação nacional. Lei nº394, de 20/12/96, em seu título II, artigo $2^{\circ}$.

QUEIROZ, Renato da Silva. Não vi e não gostei: o fenômeno do preconceito. São Paulo. Editora Moderna, 1996.

SILVA, Geane de Jesus. Bullying: quando a escola não é um paraíso. Revista Mundo Jovem. Porto Alegre, n. 365, p. 2-3, 2006.

SILVA, Mônica. Bullying: O que é e como proceder. Disponível em: www.profala.com/arteducesp146.htm. Acessado em 15 de janeiro 2013.

VASCONCELLOS, Maria Lúcia M. Carvalho (Org.). (In) Disciplina, Escola e Contemporaneidade. São Paulo, Editora Mackenzie, 2001. 